\title{
Die gemalte Zeit
}

\section{Erhard Taverna}

Dr. med., Mitglied der Redaktion

Die ausgestellten Gemälde sind meist monochrom, Schwarz und Weiss auf Papier, Leinwand und Metall, wenige Farbtöne. Mehrere Farbschichten übereinander gemalt verleihen der Oberfläche eine Tiefe, nuancieren Schattierungen und Farbtöne, sei diese rau,

\section{Die formalen Reduktionen erfordern vom \\ Betrachter eine fast meditative Konzentration.}

brüchig, glatt oder spiegelnd. Aus der Tiefe drängen verborgene Strukturen ans Licht, sichtbare Verwerfungen schaffen körperliche Bild-Räume. Die formalen Reduktionen erfordern vom Betrachter eine fast meditative Konzentration. Eine Bild-Sprache möchte gelesen und entziffert werden. Wer sich auf die Feinheiten von Walter Angehrns Kunst einlässt, spürt einen eigenartigen Sog und entdeckt mit jedem Lichteinfall eine neue Perspektive. Der Maler sucht seine Werk- stoffe gerne im Baumarkt. Lacke, Teer, Lampenruss, Leim und Acryl, transparent lasierend bis pastos aufgetragen, materialisieren die zu entdeckenden inneren und äusseren Räume.

\section{Vom Hausarzt zum Künstler}

Zehn Jahre sind vergangen, seit Walter Angehrn seine Hausarztpraxis in St. Gallen nach langem, zähem Ringen zugunsten der Kunst aufgegeben hat. Nicht nur zur Freude von Kollegen und selbst einiger Freunde, die diesen Schritt nicht billigen konnten oder wollten. Die neue Existenz begann mit einem schmerzhaften Ablösungsprozess von einem geliebten Beruf, mit Existenzängsten und den Selbstzweifeln eines Autodidakten, auf den in der Kunstszene niemand gewartet hatte. Die langjährige, durchstrukturierte, anerkannte ärztliche Tätigkeit wechselte fast übergangslos zu einem ein-

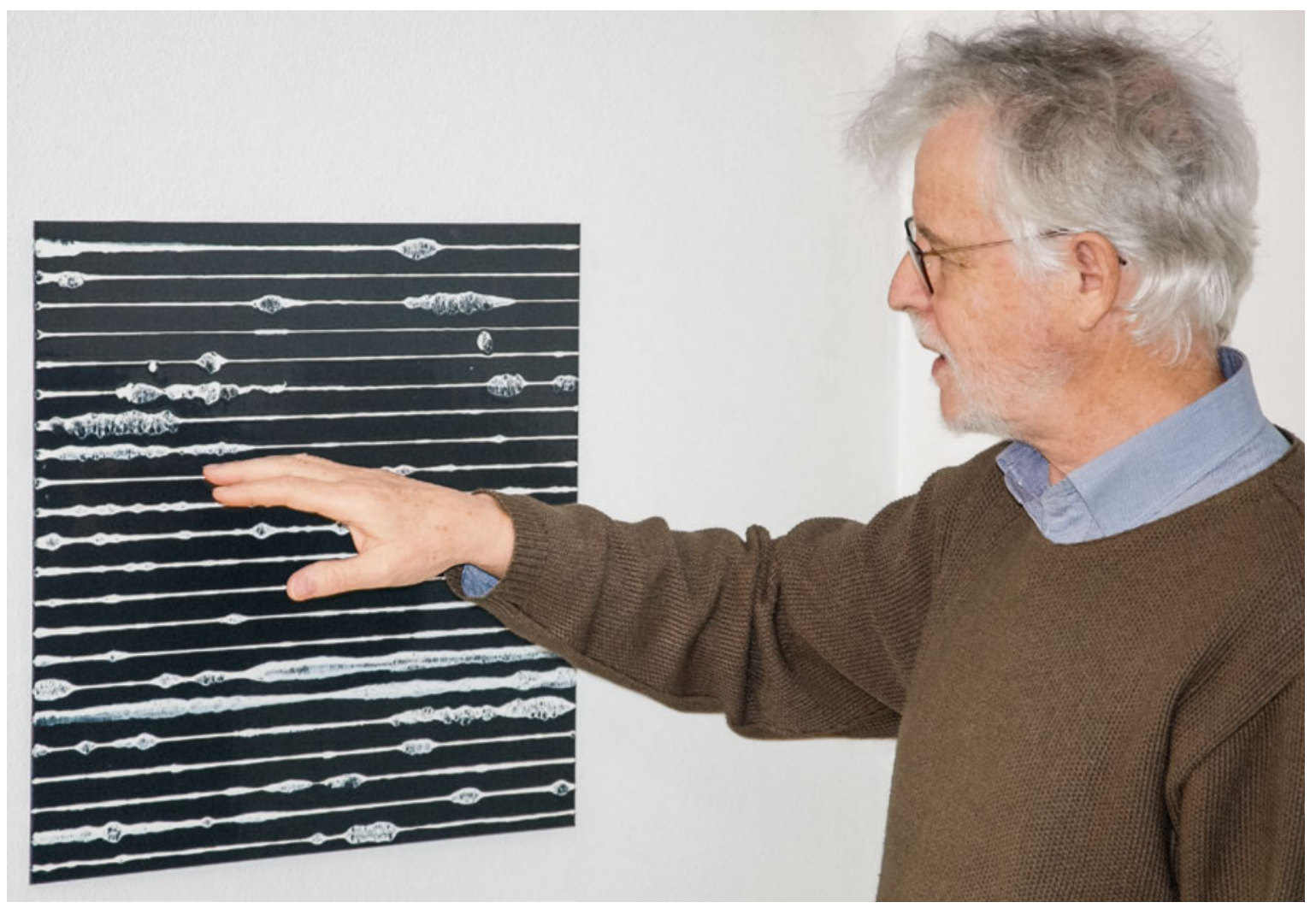

Walter Angehrn hat seine Hausarztpraxis vor 10 Jahren aufgegeben und widmet sich seither erfolgreich der Malerei. 


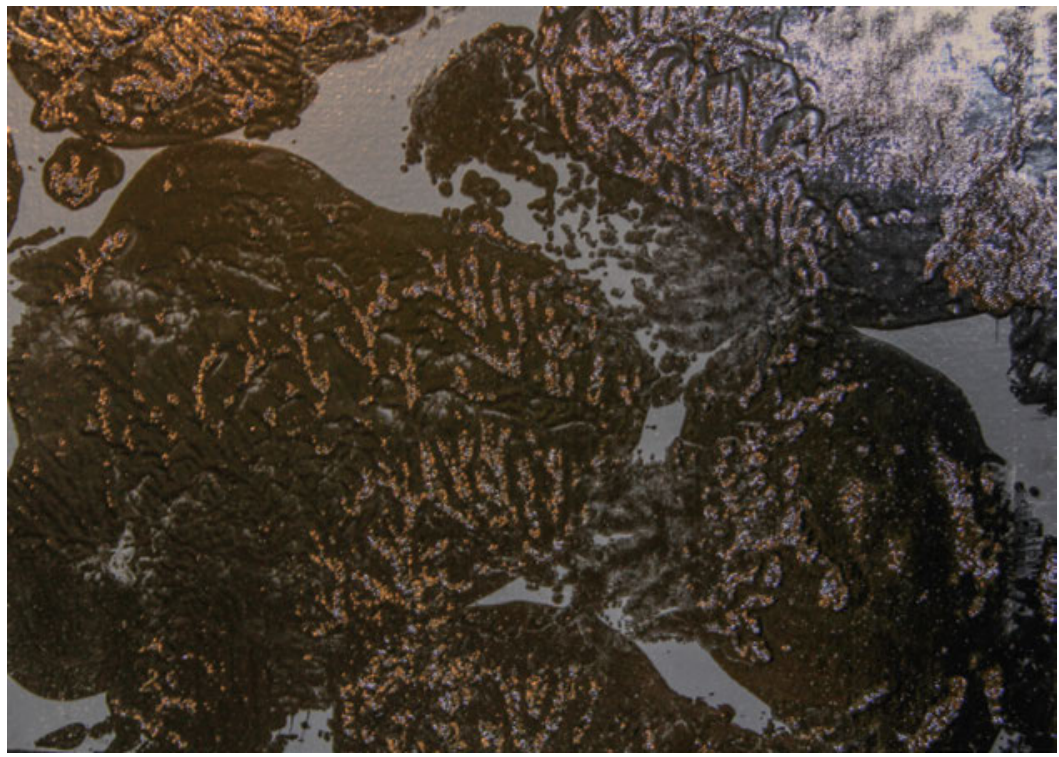

samen Leben im Atelier, mit ungewissem Ausgang. Im Dezember 2016 ist die achte Ausstellung zu Ende ge-

\section{Eine der wichtigsten Inspirationsquellen blieb stets die Lyrik.}

gangen. Mehrere hundert Besucher haben die Werkgruppen im leerstehenden Industrieraum betrachtet, Bilder wurden an Private und Institutionen verkauft. Interessant ist, dass Radiologen als Käufer seit Jahren ein besonderes Gespür zeigen. Vielleicht, weil sie berufsbedingt als geschulte Interpreten die abstrakten Schattenzeichen und Symbole besser erkennen. Auch Medien haben schon wieder- holt berichtet, und eine erfahrene Kuratorin hielt eine kluge und einfühlsame Eröffnungsrede anlässlich der letzten Vernissage.

Walter Angehrn hat etwas gewagt, wovon manche vielleicht nur träumen. Er hat die "perfekte Schatulle», wie er sein altes Leben nennt, nochmals aufgebrochen und hat sich mit Herzblut, Ausdauer und Können eine neue Existenz aufgebaut. Alles Bisherige hat darin Platz gefunden, das dreijährige Theologiestudium in Chur und Lyon, die Jahre als Sekundarlehrer, das Medizinstudium bis zum Staatsexamen 1985 in Bern, das Doktorat und die vom Allgemeinmediziner so geschätzten $\mathrm{Pa}$ tientenkontakte. Eine renommierte Galeristin prüfte Mappe um Mappe der frühen Arbeiten, bevor er sich, noch vor seinem Berufswechsel, mit seinen Bildern 2005 erstmals an die Öffentlichkeit getraute. Eine der wichtigsten Inspirationsquellen blieb stets die Lyrik. Von Sarah Kirschs «Wenn das Eis geht» bis zum kürzlich verstorbenen Werner Lutz, dessen hochkonzentrierte, verknappte Sprache Angehrns Werk am nächsten kommt. Ein in der Einladung zitiertes Gedicht von Lutz war gleichsam das Motto der letzten Ausstellung: «Eine Nachdenklichkeit/auf japanische Art glänzendschwarz lackiert/dass die verschiedensten Dunkelheiten/sich spiegeln darin». Die poetischen Landmarken haben auch eine konkrete Entsprechung in drei vom Künstler gelb markierten Steinbrocken auf einer

\section{Die Verwandlung von Raum und Zeit ist} eine Leitlinie in seinem malerischen Schaffen.

irischen Insel gefunden. Walter Angehrn hat die Verwitterung der Malzeichen über Jahre fotografiert und deren leise Auflösung zusammen mit Versen des katalanischen Dichters Ernest Farrés in der Edition land marks dokumentiert. Die Verwandlung von Raum und Zeit ist eine Leitlinie in seinem malerischen Schaffen. Für dieses nur selten spürbare essentielle Zeiterleben sucht und findet Walter Angehrn Metaphern, die uns aus dem Fluss der Zeit das Jetzt und die Kostbarkeit des Augenblicks erahnen lassen. Wer sich seiner Intuition überlässt, bekommt eine Botschaft mit auf den Weg. Das Unbegreifliche, Unsagbare fühlbar zu machen, ist nach Ansicht des französischen Philosophen Jean-François Lyotard die Aufgabe der Kunst. Walter Angehrn macht uns vor, wie das geht.

\section{Hinweis}

Die Editionen können direkt beim Künstler bezogen werden. www.walterangehrn.ch

\section{Bildnachweise}

Walter Angehrn 